\title{
Flaubert, par Bernard Fauconnier
}

\section{Maria Emanuela Raffi}

\section{(2) OpenEdition}

\section{Journals}

\section{Edizione digitale}

URL: https://journals.openedition.org/studifrancesi/3165

DOI: 10.4000/studifrancesi.3165

ISSN: 2421-5856

\section{Editore}

Rosenberg \& Sellier

\section{Edizione cartacea}

Data di pubblicazione: 1 juillet 2013

Paginazione: 478

ISSN: 0039-2944

\section{Notizia bibliografica digitale}

Maria Emanuela Raffi, «Flaubert, par Bernard Fauconnier», Studi Francesi [Online], 170 (LVII | II) | 2013, online dal 30 novembre 2015, consultato il 02 février 2023. URL: http://journals.openedition.org/ studifrancesi/3165 ; DOI: https://doi.org/10.4000/studifrancesi.3165

\section{Questo documento è stato generato automaticamente il 2 février 2023.}

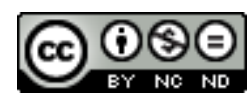

Creative Commons - Attribuzione - Non commerciale - Non opere derivate 4.0 Internazionale - CC BY NC-ND 4.0

https://creativecommons.org/licenses/by-nc-nd/4.0/ 


\title{
Flaubert, par Bernard Fauconnier
}

\author{
Maria Emanuela Raffi
}

\section{NOTIZIA}

Flaubert, par BERNARD FAUCONNIER, Paris, Gallimard (Folio biographies), 2012, pp. 290.

1 Questa biografia di Flaubert, pubblicata da Bernard Fauconnier, traccia il percorso di un'esistenza tutta vissuta all'insegna di un desiderio prepotente e quasi tirannico: quello della scrittura e della sua realizzazione in una serie di opere straordinarie e sofferte. Tutto il resto, che pure non è poca cosa - dalla lunga e tormentata relazione con Louise Colet al viaggio in Oriente con Maxime Du Camp, alla perdita di amici cari come Louis Bouilhet - appaiono solo come una sorta di cornice alle continue esaltazioni e preoccupazioni per la realizzazione di Madame Bovary prima, di Salammbô, dell'Education sentimentale e della Tentation poi e via via fino alle ultime opere. Fauconnier segue con attenzione appassionata, fondandosi spesso sulle lettere di Flaubert, questo itinerario di vita e di scrittura, in cui anche gli avvenimenti più dolorosi non riescono ad incidere sulla preoccupazione letteraria: «Dans les mois qui suivent le decès de sa mère, Gustave s'enferme dans une solitude de plus en plus farouche. Seul lui importe son Saint Antoine». L'indignazione accompagna spesso i suoi ultimi anni, soprattutto per l'ingresso all'Académie di alcuni scrittori insospettabili e stimati come Taine e Renan o del suo caro amico Du Camp, con cui tante volte aveva deriso, in giovinezza, l'istituzione seguendo la massima, coniata da lui stesso: «Les honneurs déshonorent, le titre dégrade, la fonction abrutit». 